\title{
A pioneer of urologic surgery from a small town in Ontario, Canada: A tribute to Abraham Groves (1847-1935)
}

\author{
Yves Caumartin, MD; Vivian C. McAlister, MD; Patrick P.W. Luke, MD, FRCSC
}

See related article on page 413.

\section{Abstract}

Background: Abraham Groves worked as a general practitioner and surgeon in the small town of Fergus, Ontario, Canada. Several priority claims have been attributed to Groves' life in surgery, including aseptic surgery (1874), appendectomy (1883) and the use of surgical gloves (1885). He was also an early practitioner of urological surgery.

Objective: The purpose of this paper is to describe and objectively assess his contributions as a pioneer in urological surgery.

Methods: A systematic search of contemporary journals was made for articles by or about Groves. These articles and his 1934 autobiography were reviewed. The information was assessed not only for priority, but also for the development of organized surgical principles and thought.

Results: Groves published frequently throughout his career; up to this point, 36 papers have been identified. Groves' claims are verifiable for aseptic surgery, which were the result of logical surgical thought and was practiced throughout his career. Contemporary publications support his early use of suprapubic lithotomy (1875), prostatotomy (1887), bladder repair (1892), urethral repair (1903), renal decapsulation (1905) and prostatectomy (1911).

Conclusions: Despite his isolation, Abraham Groves independently developed a full range of surgical techniques and principles relevant to modern-day urology. His impact was reduced by the nature of the environment in which he worked and by the limited circulation of the journals in which he chose to publish.

Can Urol Assoc J 2010;4(6):407-12

\section{Résumé}

Contexte : Abraham Groves était omnipraticien et chirurgien dans la petite ville de Fergus, en Ontario. Plusieurs percées importantes lui ont été attribuées, comme la chirurgie en asepsie (1874), I'appendicectomie (1883) et l'emploi de gants chirurgicaux (1885). Il a aussi été un pionnier de la chirurgie urologique.

Objectif : Le présent article vise à décrire et évaluer de façon objective les contributions d'Abraham Groves dans l'évolution de la chirurgie urologique.

Méthodologie : Une recherche systématique des revues médicales de l'époque a permis de dégager des articles signés par Groves ou portant sur ses travaux. On a ensuite passé en revue ces articles et son autobiographie, datant de 1934. On cherchait dans ces documents non seulement des preuves de ses percées sur le plan scientifique mais aussi l'élaboration de principes et théories structurés en chirurgie.

Résultats : Groves a publié de nombreux articles; jusqu'à présent, nous en avons trouvé 36 . Il a été possible de confirmer les découvertes de Groves concernant la chirurgie en asepsie, technique découlant de la logique scientifique et qu'il a pratiquée durant toute sa carrière. Des articles de l'époque confirment son utilisation de la lithotomie sus-pubienne (1875), de la prostatotomie (1887), de la réparation vésicale (1892), de la réparation urétrale (1903), de la décapsulation rénale (1905) et de la prostatectomie (1911). Conclusions : En dépit de son isolement, Abraham Groves a élaboré de façon indépendante une gamme de techniques chirurgicales et de principes toujours pertinents en urologie de nos jours. Son influence a été limitée par la nature de son environnement professionnel et par la circulation limitée des périodiques dans lesquels il a choisi de publier.

\section{Introduction}

A brief historical overview of Groves' life can help to understand how this "backwood" doctor independently developed an organized surgical system with a resulting exceptional surgical career (Fig. 1). Abraham Groves was born on September 8, 1847 near Peterborough, Ontario, Canada, from Irish immigrant parents. In 1856, the Groves family moved to a 200-acre farm, 4 miles from Fergus, Ontario. ${ }^{1,2}$ After he finished high school, he left home in 1867 to register in the Toronto School of Medicine.

During this time, medical education in Toronto was going through a difficult period. The practical bedside training was fragmented and inadequate. The Toronto General Hospital had to close in 1868 to 1869 due to lack of funds. Groves had less than 6 months of apprenticeship as an assistant to a Toronto doctor before beginning his practice in 1871 in his hometown of Fergus, Ontario. Thirteen classmates of Groves, including William Osler, graduated elsewhere to complete their clinical training. ${ }^{1,2}$

At the time, abdominal surgeries were associated with significant complications and mortality, and avoided by the academic surgeons. Groves recounted: "during my 
Caumartin et al.

undergraduate course there was not, so far as I know, one abdomen opened in the Toronto General Hospital." ${ }^{3}$ This made his inauguration as a surgeon, after 3 years of general practice, even more extraordinary when he operated on a 40-year-old woman with cystic ovarian tumour filling the entire abdomen in $1874 . .^{3,4}$

During his 60 year career, he performed over 20000 operations. His belief regarding preventive medicine, including abstinence from alcohol or tobacco, allowed him to maintain his own health until he died in 1935 from pneumonia at the age of $87.1,2,5$

Several priority claims have been attributed to Groves, including aseptic surgery (1874), ${ }^{4}$ appendectomy $(1883)^{3}$ and the use of surgical gloves (1885). ${ }^{3}$ His contributions as a pioneer in urology are less well-known. In this paper, these priority claims will be presented and discussed in relation to the history of urologic surgery.

\section{Methods}

A systematic search of contemporary journals was made for articles by or about Abraham Groves. These articles, as well as his 1934 autobiography All in the Day's Work, ${ }^{3}$ were reviewed. Overall, Groves published 36 medical papers

Table 1. Groves' medical publications

\begin{tabular}{|c|c|c|c|}
\hline & Journal name & Article title & Date \\
\hline 1 & Canada Lancet & Case of ovariotomy ${ }^{4}$ & 1874 \\
\hline 2 & Canada Lancet & Case of ovariotomy ${ }^{24}$ & 1875 \\
\hline 3 & Canada Lancet & A case of double ovariotomy ${ }^{25}$ & 1878 \\
\hline 4 & Canadian Journal of Medical Science & Supra-pubic lithotomy ${ }^{11}$ & 1881 \\
\hline 5 & Canadian Practitioner & Removal of firmly adherant solid tumour ovary ${ }^{26}$ & 1883 \\
\hline 6 & Northwest Lancet & Puerperal septicaemia ${ }^{27}$ & 1883 \\
\hline 7 & Canadian Practitioner & The operative treatment of fluid effusions of the chest ${ }^{28}$ & 1884 \\
\hline 8 & Canadian Medical and Surgical Journal & Empyema $^{29}$ & 1884 \\
\hline 9 & Canada Lancet & Renal calculi ${ }^{23}$ & 1885 \\
\hline 10 & Canada Lancet & Prostatotomy ${ }^{13}$ & 1887 \\
\hline 11 & Canadian Practitioner & Prostatotomy ${ }^{14}$ & 1887 \\
\hline 12 & Canadian Medical and Surgical Journal & Prostatectomy ${ }^{15}$ & 1887 \\
\hline 13 & Canada Lancet & Vaginal hysterectomy with abdominal ovariotomy ${ }^{30}$ & 1889 \\
\hline 14 & Montreal Medical Journal & Peri-typhlitic abscess ${ }^{31}$ & 1890-1891 \\
\hline 15 & Canada Lancet & Immediate closure of the wound after supra-pubic cystotomy ${ }^{12}$ & 1892 \\
\hline 16 & Dominion Medical Monthly & Laparo-elytrotomy ${ }^{32}$ & 1893 \\
\hline 17 & Eclectic Medical Journal & Extrauterine pregnancy ${ }^{33}$ & 1895 \\
\hline 18 & Montreal Medical Journal & The local treatment of intrauterine sepsis ${ }^{34}$ & 1899 \\
\hline 19 & Canada Lancet & The action of $x$-rays in diseased structures ${ }^{35}$ & 1903 \\
\hline 20 & Canada Lancet & Estlanders operations - 3 cases $^{36}$ & 1903 \\
\hline 21 & Canada Lancet & Diagnosis and treatment of tuberculous peritonitis ${ }^{37}$ & 1903 \\
\hline 22 & Dominion Medical Monthly & Operation for traumatic epilepsy ${ }^{38}$ & 1903 \\
\hline 23 & Dominion Medical Monthly & Appendiceal diseases ${ }^{39}$ & 1903 \\
\hline 24 & American Medicine & Operative treatment of the ruptured urethra ${ }^{18}$ & 1903 \\
\hline 25 & Dominion Medical Monthly & Intestine ruptures by kick of a horse $\mathrm{e}^{40}$ & 1903 \\
\hline 26 & Canadian Practice and Review & The radical cure of hernia ${ }^{41}$ & 1904 \\
\hline 27 & Canadian Practitioner & Radical cure of hernia ${ }^{42}$ & 1904 \\
\hline 28 & Canada Lancet & Intra-abdominal anastomosis ${ }^{43}$ & 1904-1905 \\
\hline 29 & American Medicine & Intra-abdominal anastomosis ${ }^{44}$ & 1905 \\
\hline 30 & Canada Lancet & $\begin{array}{l}\text { Case of acute uraemia in which decapsulation of the kidney was } \\
\text { performed }^{19}\end{array}$ & 1905-1906 \\
\hline 31 & Canada Lancet & Thyroidectomy ${ }^{45}$ & 1907 \\
\hline 32 & Canada Lancet & Pyloroplasty ${ }^{46}$ & 1909 \\
\hline 33 & Canada Lancet & Prostatectomy ${ }^{16}$ & 1911-1912 \\
\hline 34 & CMAJ & Evolution of surgery ${ }^{10}$ & 1922 \\
\hline 35 & CMAJ & Rupture of the bladder ${ }^{47}$ & 1923 \\
\hline 36 & CMAJ & $\begin{array}{l}\text { Fracture of the clavicle, acromium process and surgical neck of the } \\
\text { scapula }^{48}\end{array}$ & 1924 \\
\hline
\end{tabular}




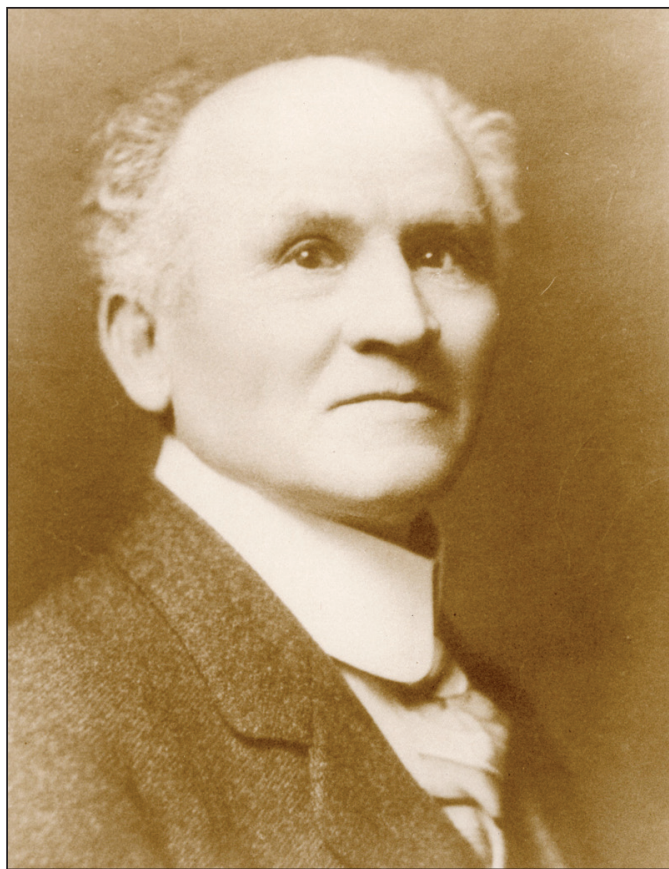

Fig. 1. Portrait of Dr. Abraham Groves, circa 1920 (Wellington County Museum and Archives, ph 10150).

from 1874 and 1924 (Table 1). Articles were identified through the Index-Catalogue of the Library of the SurgeonGeneral's Office (US army, Series 1-5). Eleven scholarly and 3 newspaper articles (Toronto Globe, Toronto Star and Fergus Record) about Groves were published between 1948 and 2003. Additionally, material was found in 5 archives (Wellington County Museum, Ontario Medical Association, Archives of Ontario, Dittrick Museum in Cleveland and Toronto Academy/Toronto General Hospital). The information relevant to urologic surgery field was collected and assessed not only for priority claims, but also for the development of organized surgical principles and thought.

\section{Results}

Groves published frequently throughout his career; 36 papers have been found (Table 1). He spoke at regional meetings in Ontario, but not in the United States. He was a founding member of the Ontario Medical Association, but not of the American College of Surgeons.

\section{Aseptic surgical technique}

It is likely that the early adoption of aseptic techniques permitted him to succeed in urologic surgery. Prior to his first major operation in May 1874, ${ }^{4}$ Groves was advised by colleagues to avoid the procedure. At that time, he knew that typhoid fever could result from drinking water that appeared pure. Groves reasoned that since typhoid was carried by

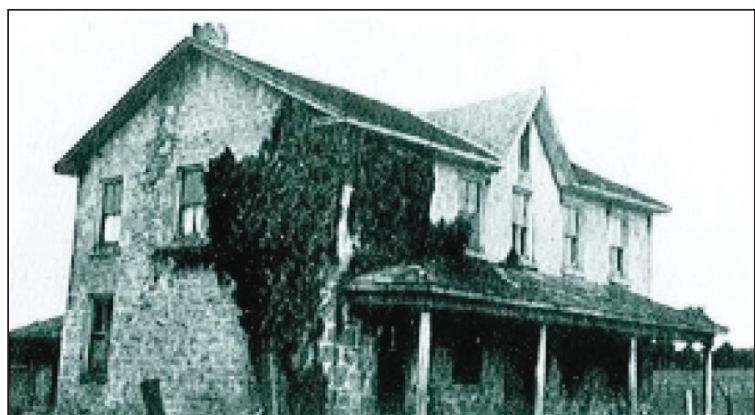

Fig. 2. The Bullfrog Tavern (Guelph, Ontario) where Groves proceeded to his first suprapubic lithotomy (taken from $A / l$ in the Day's Work). The tavern still exists today as a barber shop.

water, infections after surgery might arise from infected fluids of the patient, the surgeon's hands, the instruments or the sponges. To minimize infection, he decided to boil the water used during operations and allowed it to cool. In this way, all his instruments and sponges were boiled. Carbolized catgut was also used to tie vascular pedicles and cotton saturated with a solution of carbolic acid was used to dress the wounds. ${ }^{2-4}$

It is not precisely known when the first description of aseptic surgery was documented. Lister, perceiving that Pasteur's heat sterilization had no relevance to surgical procedures, turned to chemical antisepsis with carbolic acid by 1867. Koch and his assistants perfected the idea of steam sterilization in $1881 .{ }^{6}$ However, heat sterilization was not truly introduced into surgery until Von Bergmann described it in 1886, 12 years after Groves' description. ${ }^{7}$ It was not until 1888 that Davidsohn consistently taught surgeons in the United States to boil their instruments. ${ }^{8}$

\section{Suprapubic lithotomy}

Bladder stones had been treated through perineal extraction for centuries. While the suprapubic approach was documented for the first time by Pierre Franco in 1556 and subsequently by John Douglas among others; this approach, however, was not generally approved for stone extraction and was virtually unknown among contemporary surgeons. ${ }^{9}$ For his first stone extraction, Groves proceeded through a suprapubic route. His description of 4 cases was a first in Canada. ${ }^{3,10}$

His first suprapubic cystolithotomy involved a 63-yearold man weighing over 300 pounds. Surgeons of the highest standing had refused to operate on him, believing that the perineal route would not provide access to the bladder. Groves, however, performed the suprapubic cystolithotomy on April 20, 1878, in a room of an old hotel, the Old Bullfrog tavern in Guelph, Ontario (Fig. 2). Assisted by 2 medical students, he removed 6 calculi (Fig. 3). After this groundbreaking procedure, the patient promptly recovered without complication. ${ }^{11}$ 


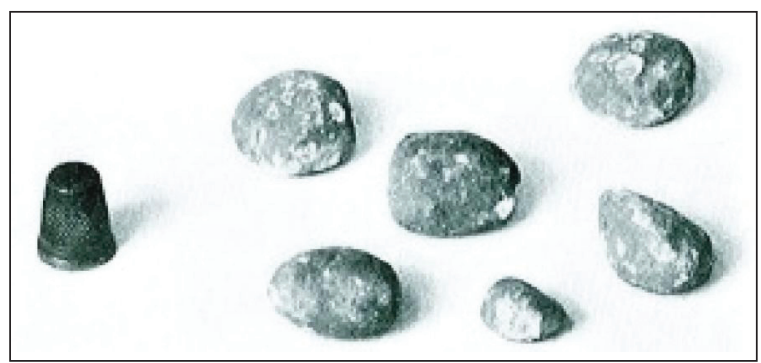

Fig. 3. The 6 bladder calculi removed by the suprapubic route, in 1878 (taken from All in the Day's Work).

In cases involving bladder stones, the bladder was usually in an unhealthy condition, containing "ropy mucus, pus, cast-off epithelium, decomposing blood clots or fetid urine." However, Groves realized that "... immediate union [of the wound] is the ideal result we are striving for...on account of the constant escape of urine through an open wound..."3

In 1892, Groves described his technique of immediate wound closure after suprapubic cystotomy. ${ }^{12}$ First, to obtain a cleaner surgical field, Groves performed antiseptic cleansing of the bladder. Using Thiersch's solution of salycilic and boracic acids, the bladder was irrigated with copious and repeatedly washed for a number of days. Finally, the whole wound was flushed with bichloride solution and the bladder was closed with continuous catgut suture. To prevent rupture of the ill-conditioned bladder, drainage was provided through a catheterization system similar to contemporary catheter management.

\section{Prostatotomy}

In 2 publications, ${ }^{13,14}$ Groves demonstrated an advanced knowledge of anatomy and the physiopathology of prostate enlargement. Despite the fact that the prostatotomy procedure is currently performed endoscopically (transurethral incision of prostate), the principles behind his approach reflect current therapy.

Prostatotomy was performed early in Groves' practice. The patient was placed in the lithotomy position, and a grooved staff passed into the bladder. The skin incision was made in the median perineal line, and the membranous portion of the urethra opened as close to the prostate as possible. Then an ordinary lithotomy knife was passed along the grooved staff and the obstructing portion of the prostate incised (Fig. 4). A drain was inserted and the staff was withdrawn; the patient recovered with prolonged bedrest to prevent dislodgement of the drain. ${ }^{13,14}$

\section{Prostatectomy}

Through his experience with suprapubic lithotomy, Groves progressively mastered the suprapubic approach for urologic disease. ${ }^{15}$ A publication from 1911 reported his experience

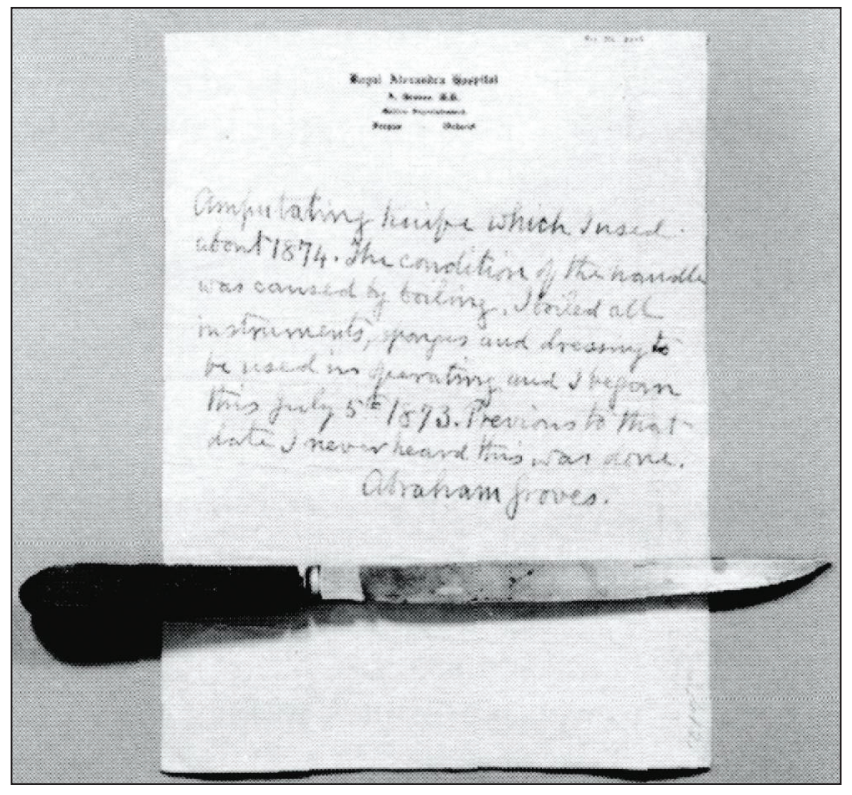

Fig. 4. Groves' amputation knife. Quoting Groves: ' ... the handle split and loosened. This was caused by my boiling every instrument and all things used in an operation (taken from the Dittrick Museum of Medical History of the Cleveland Medical Library Association).

with transvesical prostatectomy. ${ }^{16}$ There are sources that indicate that Groves performed the first prostatectomy in $1887,{ }^{15}$ the same year it was reported by McGill in Leeds, UK and 4 years prior to Goodfellow who described perineal prostatectomy. ${ }^{17}$ To the best of our knowledge, there are no documents that describe Groves' surgical technique and no documentation of the location and exact time of the first procedure. According to modern texts, neither McGill, Goodfellow nor Groves were granted credit for the first prostatectomy. This distinction was given to Fuller in 1894 and popularized by Freyer in 1900. It was not until 1947 that the contemporary open approach was described in detail by Millin.

In Groves' publication on prostatectomy, he described the surgical principles behind prostatectomy, but did not document anatomical or surgical details about the prostatectomy procedure. He stated merely that he preferred the suprapubic over the perineal approach, due to improved exposure to the prostate through the suprapubic approach. He stated that "since the prostate enlarged towards the bladder and not towards the perineum," the suprapubic approach could facilitate the removal of the adenoma. ${ }^{3}$ He reported a remarkably low mortality rate for the time: only 3 of 100 patients died from pneumonia, prostate cancer and sepsis.

\section{Urethral repair}

In a short article published in American Medicine in 1903,, ${ }^{18}$ Groves described the operative treatment of a ruptured urethra. Again, his description adopted principles employed 
by modern-day urologists. He indicated that extravasation of blood and urine in the bruised and torn tissues rendered reconstruction of the urethra after pelvic trauma a daunting task. In managing urethral injury, he described a combined suprapubic and perineal approach. This involved antegrade passage of a catheter from the open bladder along the urethra to localize the proximal urethra. He also commented on the resulting problem associated with delayed surgical repair: "if the edges are not approximated, cicatricial tissue will results and a troublesome stricture develop." ${ }^{3} \mathrm{He}$ also found success with delayed reconstruction of the urethra.

\section{Renal decapsulation}

In 1903, Groves published a case of decapsulation of kidneys performed in a patient with acute nephritis. ${ }^{3,19}$ Despite the fact that this procedure is not currently in vogue, renal decapsulation later developed interest and its merits reviewed in CMAJ in 1940 as a treatment for various inflammatory conditions of the kidneys including Bright's disease. ${ }^{20}$ The first case was performed by Harrison, of England, in 1878, but was elaborately discussed for the first time by Edebohls in 1901, who later received credit in conceptualizing this surgery. ${ }^{21}$ It is not clear if Groves was aware of these reports at the time he published his first case, but through this publication, he introduced novel concepts regarding parenchymal compression, impaired blood flow and renal failure that were unrecognized concepts at that time.

To Groves, the inability of the kidneys to secrete any urine stemmed from their encasement in the inelastic capsule. Therefore, as the kidneys swelled from intense congestion and inflammation, they were unable to function on account of pressure. Although surgical capsulotomy has not been proven to be beneficial to treat nephritis or pyelonephritis, Groves clearly had a grasp of renal physiology and surgical principles that were not well-described until Page published his physiology paper in $1939 .{ }^{22}$

\section{Renal calculi}

As a general practitioner, Groves developed principles for disease prevention. Early in his career, he published a paper on the etiology of renal calculi and treatment strategies. ${ }^{23}$ Although based on other authors' works, his understanding of urolithiasis was remarkably advanced.

In his publication, he approached many different aspects of this disease. He mentioned the inadequate supply of milk as a cause for stone formation in certain population. He also stated that the hardness of the water increases the risk for stone formation and noted that foreign bodies can act as a nucleus for stone formation.

He concluded this paper by addressing the treatment of renal colic. Belladonna, opium and warm baths were part of the regular treatment. He advised the administration of an anesthetic in every case in which pain was too severe. Blood letting performed during this era was condemned by Groves and deemed to be entirely unnecessary. Finally, he suggested that regulation of diet, drinking considerable quantities of lime-free water, exercise and avoidance of alcoholic liquors could prevent stone formation.

\section{Conclusion}

Groves' adoption of aseptic surgery enabled him to develop a very complex surgical practice that including a well-developed practice in urology. However, his impact was reduced by nature of the environment in which he worked and by the limited circulation of the journals in which he chose to publish. If Groves had Osler's opportunity and foresight to write a book entitled Principles and Practice of Urology in 1892, we may have considered him to be a founding father of modern urology.

Department of Surgery, Divisions of General Surgery and Urology, University of Western Ontario, London, ON

Competing interests: None declared.

This paper has been peer-reviewed.

\section{References}

1. Harris CW. Abraham Groves of Fergus: the First Elective Appendectomy? Can J Surg 1961;4:405-10.

2. Spaulding WB. Abraham Groves (1847-1935): A Pioneer Ontario Surgeon, Sufficient unto himself. Can Bull Med Hist 1991;8:249-62.

3. Groves A. All in the Day's Work. Toronto, ON: McMillan Publishing Company; 1932.

4. Groves A. Case of ovariotomy. Canada Lancet 1874;6:345-7.

5. Sanders P. Abraham Groves. Surg Gynecol Obstet 1987;164:179-84.

6. Godfrey CM. Inaugural Meeting of 1881 revisited. Ontario Medical Review 1980:309.

7. Garrison FH. An Introduction to the History of Medicine. 4th ed. Philadelphia, PA: W.B. Saunders; 1929.

8. Ravitch MM. A Century of Surgery. Philadelphia, PA: J.B. Lippincott; 1981.

9. Androutsos G. Pierre Franco (1505-1578): famous surgeon and lithotomist of the 16th century [article in French]. Prog Urol 2004; 14:255-9.

10. Groves A. Evolution of surgery. CMAJ 1922;12:527-31.

11. Groves A. Supra-pubic lithotomy. Can J Med Sci 1881;4:354.

12. Groves A. Immediate closure of the wound after supra-pubic cystotomy. Canada Lancet 1892;25:44-5.

13. Groves A. Prostatotomy. Canada Lancet 1887;12:240-1.

14. Groves A. Prostatotomy. Canadian Practitioner 1887;12:240.

15. Groves A. Prostatectomy. Canadian Medical and Surgical Journal 1887;15:715.

16. Groves A. Prostatectomy. Canada Lancet 1911;45:572.

17. Shackley D. A century of prostatic surgery. BJU Int 1999:83:776-82.

18. Groves A. Operative treatment of the ruptured urethra. American Medicine 1903;5:410.

19. Groves A. Case of acute uremia in which decapsulation of the kidneys was performed. Canada Lancet 1905;39:609-10

20. Nichol JE. Indications for decapsulation of the kidney. CMAJ 1940;43:577.

21. Goodfellow G, Eaton GL. Decapsulation of the kidney for chronic Bright's disease. Cal State I Med 1903; 1:391. 
Caumartin et al.

22. Page IH. The production of persistent arterial hypertension by cellophane perinephritis. JAMA 1939;113:2046-8

23. Groves A. Renal calculi. Canada Lancet 1885;16:360-2.

24. Groves A. Case of ovariotomy. Canada Lancet 1875;7:192-3.

25. Groves A. A case of double ovariotomy. Canada Lancet 1878;10:195.

26. Groves A. Removal of firmly adherant solid tumour ovary. Canadian Practitioner 1884;7:323.

27. Groves A. Puerperal septicaemia. Northwest Lancet 1883;13:372-4.

28. Groves A. The operative treatment of fluid effusions of the chest. Canadian Practitioner 1884;9:233-6.

29. Groves A. Empyema. Canadian Medical and Surgical Journal 1884;12:696.

30. Groves A. Vaginal hysterectomy with abdominal ovariotomy. Canada Lancet 1889;22:6

31. Groves A. Peri-typhlitic abscess. Montr Med J 1890;19:11.

32. Groves A. Laparo-elytrotomy. Dominion Medical Monthly 1893;73-4.

33. Groves A. Extrauterine pregnancy. Eclectic Medical Journal 1895;4:509-11.

34. Groves A. The local treatment of intrauterine sepsis. Montr Med J 1899;28:208-10.

35. Groves A. The action of x-rays in diseased structures. Canada Lancet 1903;36:463-4.

36. Groves A. Estlanders operations - 3 cases. Canada Lancet 1903;37:408.
37. Groves A. Diagnosis and treatment of tuberculous peritonitis. Canada Lancet 1903;38:526.

38. Groves A. Operation for traumatic epilepsy. Dominion Medical Monthly 1903;20:200.

39. Groves A. Appendiceal diseases. Dominion Medical Monthly 1903;20:311-8.

40. Groves A. Intestine ruptures by kick of a horse. Dominion Medical Monthly 1903:20:201.

41. Groves A. The radical cure of hernia. Canadian Practice and Review 1904;29:68-71.

42. Groves A. Radical cure of hernia. Canadian Practitioner 1904:29:68.

43. Groves A. Intra-abdominal anastomosis. Canada Lancet 1904;38:407-9.

44. Groves A. Intra-abdominal anastomosis. American Medicine 1905:9:697-700.

45. Groves A. Thyroidectomy. Canada Lancet 1907;41:524-9.

46. Groves A. Pyloroplasty. Canada Lancet 1909:43:341.

47. Groves A. Rupture of the bladder. CMAJ 1923;13:319-20.

48. Groves A. Fracture of the clavicule acromium process and surgical neck of the scapula. CMAJ 1924;14:318.

Correspondence: Dr. Patrick Luke, London Health Sciences Centre, University Campus, 339 Windermere Rd, London, ON N6A 5A5; fax: 519-663-3858; patrick.luke@|hsc.on.co 


\title{
COMMENTARY
}

\section{A true surgical pioneer}

\author{
Ian Davis, MD, FRCSC
}

See related article on page 407.

Can Urol Assoc J 2010;4(6):413

would like to congratulate and thank the authors for contributing what I believe to be the first significant paper on the history of urology published in the Canadian Urological Association Journal. ${ }^{1}$ The relatively unknown Dr. Abraham Groves is an excellent choice.

Dr. Groves was a true surgical pioneer (Fig. 1). With his early adoption of the concept of asepsis and his remarkable comprehension of surgical principles, he was able to safely perform procedures unavailable in major centres. This is quite remarkable when he really had only 6 months of surgical training. In his time, a surgical apprenticeship usually involved just watching the professor and accepting his word as dogma. A lot has changed!

Dr. Groves did publish a number of articles on his accomplishments, but only in local journals. As a result few people know of his accomplishments. It is truly unfortunate that he did not work in a more academic environment where his knowledge would have been better recognized and disseminated; if so, more people could have learned from his skills.

Dr. Groves could easily be considered the Father of Canadian Urology.

Historian Emeritus, Canadian Urological Association, Hamilton, ON

Competing interests: None declared.

This paper has been peer-reviewed.

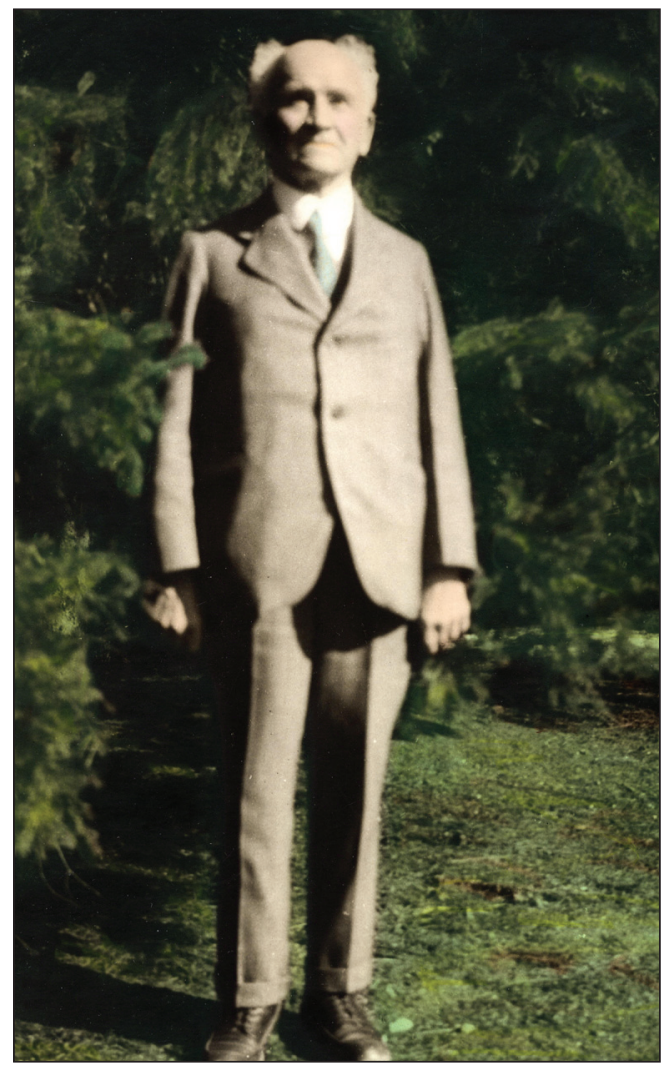

Fig. 1. Dr. Abraham Groves, circa 1931 (Wellington County Museum and Archives, ph 11728).

\section{Reference}

1. Caumartin Y, McAlister VC, Luke PPW. A pioneer of urologic surgery from a small town in Ontario, Canada: A tribute to Abraham Groves (1847-1935). Can Urol Assoc J 2010;6:407-12.

Correspondence: Dr. lan Davis, Clinical Assistant Professor, Department of Surgery, 662 Concession St., Hamilton, ON L8V 1B8; fax: (905) 574-5234; iandavisuro@@hotmail.com 